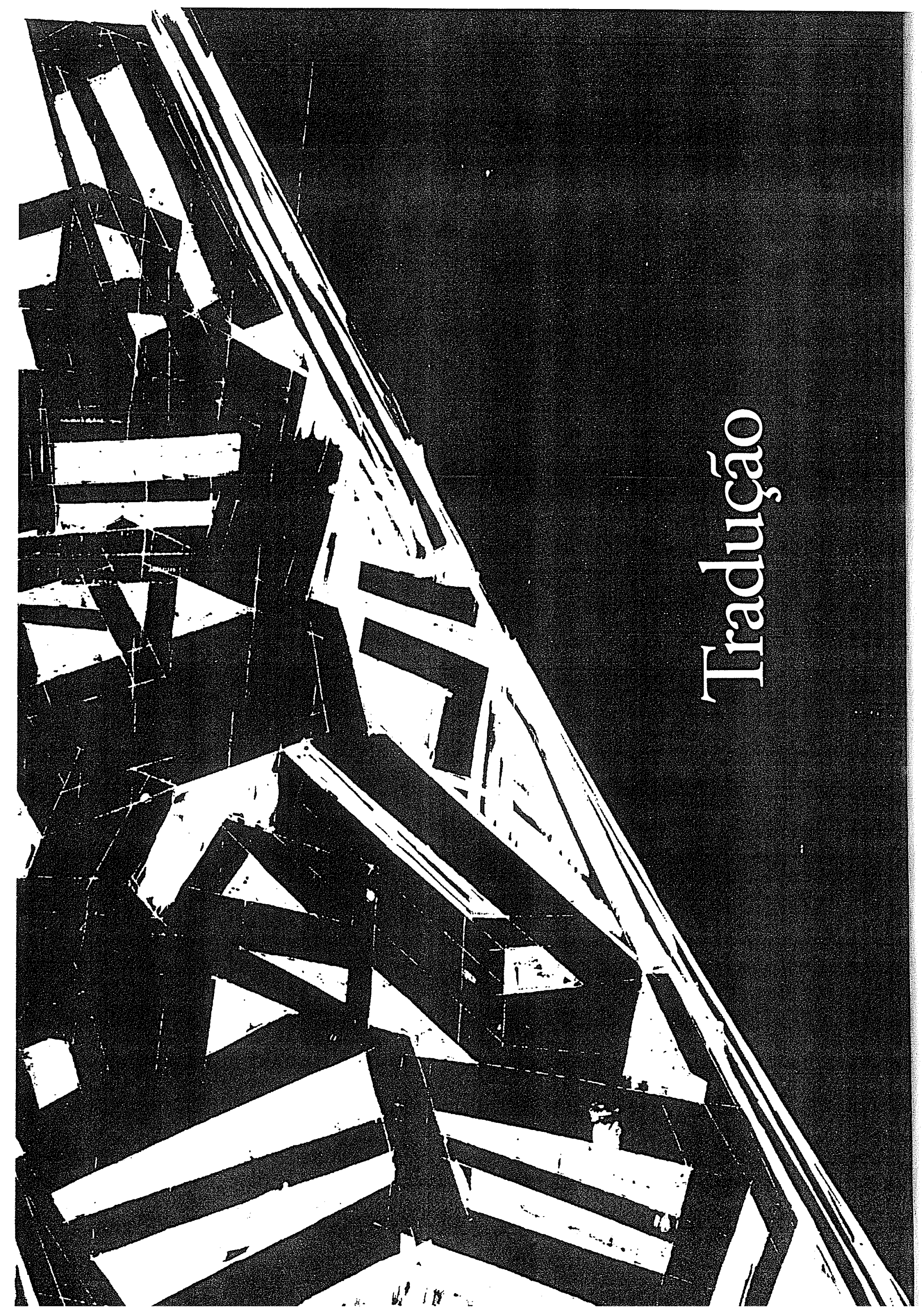




\section{Quatro poemas de Cesare Pavese ${ }^{1}$}

\author{
Tradução de Maurício Santana Dias²
}

\section{LO STEDDAZZU}

L'uomo solo si leva che il mare è ancor buio e le stelle vacillano. Un tepore di fiato sale su dalla riva, dov'è il letto del mare, e addolcisce il respiro. Quest'è l'ora in cui nulla può accadere. Perfino la pipa tra i denti pende spenta. Notturno è il sommesso sciacquío. L'uomo solo ha già acceso un gran fuoco di rami e lo guarda arrossare il terreno. Anche il mare tra non molto sarà come il fuoco, avvampante.

Non c'è cosa piú amara che l'alba di un giorno in cui nulla accadrà. Non c'è cosa piú amara che l'inutilità. Pende stanca nel cielo un stella verdognola, sorpresa dall'alba. Vede il mare ancor buio e la macchia di fuoco a cui l'uomo, per fare qualcosa, si scalda; vede, e cade dal sonno tra le fosche montagne dov'è un letto di neve. La lentezza dell'ora è spietata, per chi non aspetta piú nulla.

Val la pena che il sole si levi dal mare e la lunga giornata cominci? Domani tornerà l'alba tiepida con la diafana luce e sarà come ieri e mai nulla accadrà. L'uomo solo vorrebbe soltanto dormire. Quando l'ultima stella si spegne nel cielo, l'uomo adagio prepara la pipa e l'accende.

\footnotetext{
1 Os poemas do escritor italiano Cesare Pavese (1908-1950) traduzidos por Maurício Santana Dias fazem parte de sua tese de doutorado Lavorare Stanca: $a$ projeto impossivel de Cesare Pavese, defendida na área de Teoria Literária e Literatura Comparada (DTLLC-FFLCH-USP), e serão publicados pela Coleção Ás de colete, das editoras 7 Letras e Cosac Naify. ${ }^{2}$ Maurício Santana Dias é professor de Literatura Italiana no Departamento de Letras Modernas (DLM-FFLCH-USP).
}

\section{A ESTRELA DA MANHÃ}

0 homem só se levanta que o mar inda é escuro e as estrelas vacilam. Um mormaço de alento sobe reto das orlas, do leito do mar, abrandando o respiro. Esta é a hora em que nada acontece. 0 cachimbo entre os dentes também cai sem brilho. Noturno é o som do marulho. O homem só já acendeu uma fogueira de galhos e a observa dourar o terreno. Até o mar daqui a pouco estará como o fogo, candente.

Não tem coisa mais acre que a aurora de um dia em que nada haverá. Não tem coisa mais acre do que a inutilidade. Cansada no céu pende a estrela azulada, colhida na aurora. Olha o mar inda escuro e a mancha de fogo onde o homem, que não faz mais nada, se aquece; olha e cai de seu sono entre as foscas montanhas onde há um leito de neve. 0 arrastado das horas é inclemente com quem já não espera mais nada.

Vale a pena que o sol se levante do mar e essa longa jornada comece? Amanhã voltará a morna aurora e seu brilho diáfano e será que nem ontem e mais nada haverá. o homem só gostaria de apenas dormir. Quando a última estrela se apaga no céu, o homem lento prepara o cachimbo e 0 acende.

[9-12 de janeiro de 1936] 


\section{DOPO}

La colina è distensa e la pioggia l'impregna in silenzio.

Piove sopra le case: la breve finestra

s'è riempita di un verde piú fresco e piú nudo.

La compagna era stesa con me: la finestra

era vuota, nessuno guardava, eravamo ben nudi.

Il suo corpo segreto cammina a quest'ora ora per strada col suo passo, ma il ritmo è piú molle; la pioggia scende come quel passo, leggera e spossata.

La compagna non vede la nuda colina assopita nell'umidità: passa in strada e la gente che l'urta non sa.

\section{Verso sera}

la collina è percorsa da brani di nebbia, la finestra ne accoglie anche il fiato. La strada a quest'ora è deserta; la sola collina

\section{DEPOIS}

A colina se estende e uma chuva a encharca em silêncio.

Chove sobre os telhados: a estreita janela é tomada de um verde mais fresco e mais puro. Ao meu lado, deitada, a amiga: à janela, um vazio, e ninguém nos olhava, e estávamos nus. O seu corpo secreto caminha, a esta hora, na rua com seu passo num ritmo mais lento; e a chuva desce como esse passo, suave e cansada. Minha amiga não nota a colina despida que adormece no charco: caminha na rua e as pessoas que a esbarram não sabem.

De noite

a colina é varrida por trapos de névoa, e a janela recolhe os seus sopros. A rua a esta hora é um deserto; somente a colina tem uma vida remota no corpo mais cavo. Nós jazíamos, lassos, no sopro molhado dos dois corpos, deitados no sono, enlaçados.

Numa tarde mais doce, de tépido sol e de cores viçosas, a rua seria uma festa. É gostoso passar pela rua, gozando a memória do corpo, mas tudo difuso ao redor. $\mathrm{Na}$ folhagem das ruas, no passo indolente das moças e nas vozes de todos há um pouco da vida que os dois corpos perderam, mas que é um milagre. Descobrir lá no fundo da estrada a colina entre as casas e vê-la e pensar que ali mesmo minha amiga a contempla da estreita janela.

Mergulhou no brumoso essa pura colina e o chuvisco sussurra. Está ausente a amiga que levou com doçura o seu corpo e o sorriso. Amanhã, no céu claro e lavado da aurora, minha amiga andará pelas ruas, suave em seu passo. Podemos nos ver, se quisermos. 


\section{LA NO'TTE}

Ma la notte ventosa, la limpida notte che il ricordo sfiorava soltanto, è remota, è un ricordo. Perdura una calma stupita fatta anch'essa di foglie e di nulla. Non resta, di quel tempo di là dai ricordi, che un vago ricordare.

Talvolta ritorna nel giorno nell'immobile luce del giorno d'estate, quel remoto stupore.

Per la vuota finestra il bambino guardava la notte sui colli freschi e neri, e stupiva di trovarli ammassatti: vaga e límpida immobilità. Fra le foglie che stormivano al buio, apparivano i colli dove tutte le cose del giorno, le coste e le piante e le vigne, eran nitide e morte e la vita era un'altra, di vento, di cielo, e di foglie e di nulla.

\section{Talvolta ritorna}

nell'immobile calma del giorno il ricordo di quel vivere assorto, nella luce stupita.

[16 aprile 1938]

\section{A NOITE}

Mas a noite de ventos, a límpida noite que a lembrança roçava de leve, é remota, é lembrança. Perdura uma calma aturdida, um sossego de folhas e nada. Do tempo que ultrapassa a lembrança só resta um difuso relembrar.

Certas vezes retorna no dia, numa imóvel clareza de um dia de estio, esse espanto longínquo.

Da janela vazia o menino mirava as colinas na noite, frias e negras, e olhava espantado o maciço: vaga e límpida imobilidade. Entre as folhas farfalhando no escuro, surgiam os cerros onde todas as coisas do dia, as encostas e os vinhedos e o verde, eram claras e mortas e o viver era um outro, de vento, de céu e de folhas, de nada.

E às vezes retorna no sossego parado de um dia a lembrança dessa vida alheada na luz espantosa.

[16 de abril de 1938] 


\section{MATTINO}

La finestra socchiusa contiene un volto sopra il campo del mare. I capelli vaghi accompagnano il tenero ritmo del mare.

Non ci sono ricordi su questo viso.

Solo un'ombra fuggevole, come di nube. L'ombra è umida e dolce come la sabbia di una cavità intatta, sotto il crepuscolo. Non ci sono ricordi. Solo un susurro che è la voce del mare fatta ricordo.

Nel crepuscolo l'acqua molle dell'alba che s'imbeve di luce, rischiara il viso. Ogni giorno è un miracolo senza tempo, sotto il sole: una luce salsa l'impregna e un sapore di frutto marino vivo.

Non esiste ricordo su questo viso. Non esiste parola che lo contenga 0 accumuni alle cose passate. Ieri, dalla breve finestra è svanito come svanirà tra un istante, senza tristezza né parole umane, sul campo del mare.

[9-18 agosto 1940]

\section{MANHĨ}

A janela entreaberta contém um rosto sobre os campos do mar. Os cabelos vagos acompanham o terno balanço do mar.

Já não há mais lembranças sobre este rosto. Só uma sombra fugaz, como fosse uma nuvem. A sombra é úmida e doce como a da areia de uma intacta caverna, sob o crepúsculo. Já não há mais lembranças. Só um sussurro que é a voz desse mar tornada lembrança.

No crepúsculo a água mole da aurora que se banha de luz resplandece a face. Cada dia é um milagre sem tempo sob o sol: uma luz salgada o recobre com um vivo sabor de fruto marinho.

Não existe lembrança sobre este rosto. Não existe palavra que o contenha ou disponha entre as coisas passadas. Ontem, dessa breve janela sumiu-se como sumirá num instante, sem mais tristeza ou palavra humana, do campo do mar.

[9-18 de agosto de 1940] 